\title{
Structure of road soil cement compositions modified by complex additive based on organosilicon compounds and electrolytes
}

\author{
Lenar Mavliev* and Evgenii Vdovin \\ Kazan State University of Architecture and Engineering, Kazan, Russia
}

\begin{abstract}
The complex introduction of organosilicon compound (octyltriethoxysilane) and electrolyte (sodium hydroxide) maximizes the frost resistance and strength of soil cement. However, the effect of complex additive based on octyltriethoxysilane and sodium hydroxide on the soil cement structure has not been sufficiently studied. Therefore, the aim of this work was to study the phase composition of hydrated newgrowths and soil minerals in soil cement with optimal content of complex additives. The study was conducted by methods of complex thermal analysis, X-ray powder diffraction and electron microscopy. On the XRD pattern of the sample with and without complex additive, we marked identical peaks of soil minerals, unhydrated cement clinker minerals and hydrated newgrowths. In the result of differential thermal analysis, we determined that soil cement with complex additive is characterized by the smaller amount of free calcium hydroxide formed, as well as saturation of the soil complex with sodium ions. In the soil cement sample with complex additive, we observe a smaller amount of coagulated soil aggregates in comparison with the sample without an additive. Complex additive contributes to the formation of a more dense and uniform structure of soil cement, reduces the amount of adsorption water associated with clay minerals, reduces the formation of free calcium hydroxide, which increases the physicomechanical properties of the resulting material.
\end{abstract}

\section{Introduction}

A number of regions lack of the durable stone materials reserves, which transportation costs significantly increases the cost of road construction. We know that it is possible to refuse the use of imported crushed stone by using soil cement (soil reinforced with Portland cement) in pavement structures. Improving the efficiency and quality of soil cement [1-5] for road use is an urgent problem that cannot be successfully solved without modification by chemical additives that influence on structure and properties of resulting materials.

The most promising direction in solving this problem is the use of additives of organosilicon compounds (OSC), allowing to obtain hydrophobic and frostresistant materials, as well as electrolytes, which give high strength values to the soil cement.

Electrolytes play a large role in the formation of soil structure, cause coagulation and precipitation of the colloidal soil phase. Due to the fact that the soil is a mechanical mixture of particles with different sizes, coagulating colloidal material includes in its "flakes" and a larger pre-colloidal fraction. The replacement in the soil complex one base to another is accompanied by a profound change in the entire soil structure, and at the same time there must be great changes in its physical and mechanical properties. When the absorbing complex is saturated with divalent bases, the cations concentration in the soil solution is sufficient for particles coagulation and, therefore, is sufficient for the appearance of a microstructure in it. When the absorbing complex in the main mass is saturated with sodium, there will be no coagulation in the soil, and all individual mineral, organic and organomineral particles will exist separately. This is due to the fact that the concentration of sodium ion in the solution will lie below its electrolytic threshold due to the low coagulating ability of this cation. Consequently, the replacement of exchange cations during soil strengthening can be one of the effective methods for modifying cement grounds depending on desired goal [6-9].

Today, organosilicon compounds are widely used to modify and increase the durability of construction materials. The OSC are being fixed on the material surface, and hydrophobize the walls of pores and capillaries [10-16]. This circumstance positively affects on the improvement of frost resistance, since the adhesion of salt and ice crystals to the hydrophobic pores surface is reduced.

It is known that the chemical bond strength of polysiloxane films with the surface depends on the monomers functionality: formed films based on the of trifunctional $\mathrm{RSiX}_{3}$ monomers have a network structure and therefore the probability of their chemical interaction with the surface is greatest (for example, the octyltriethoxysilane [17]). It should also be noted that with increasing thickness of protective layer formed by OSC on the adsorbent surface, the hydrophobic effect

\footnotetext{
* Corresponding author: lenarmavliev@yandex.ru
} 
created by these compounds is enhanced. In turn, the adsorption layer thickness increases in proportion to the radical mass.

Studies of the effect of organosilicon compounds [3,4,10,18] and electrolytes [19-21] additives showed that all of them, to one extent or another, have a modifying effect. At the same time, the organosilicon compound octyltriethoxysilane (OTES) $\mathrm{C}_{8} \mathrm{H}_{17} \mathrm{Si}\left(\mathrm{OC}_{2} \mathrm{H}_{5}\right)_{3}$ addition maximized the frost resistance, and the electrolyte sodium hydroxide (SH) $\mathrm{NaOH}$ maximized soil cement strength [22]. Based on the studies, a modifying complex additive based on OTES and SH was developed. The cement consumption was $10 \%$, the dosage of OTES was $0.03 \%$, and the SH $0.1 \%$. The compressive strength up to $4.75 \mathrm{MPa}$, the bending tensile strength up to $0.96 \mathrm{MPa}$, and the frost resistance coefficient after 15 freeze-thaw cycles up to 0,86 were achieved.

However, the effect of the complex additive based on octyltriethoxysilane and sodium hydroxide on the soil cement structure has not been sufficiently studied. Therefore, the aim of this work was to study the phase composition of hydrated newgrowths and soil minerals in soil cement with the optimal content of complex additives.

\section{Methods}

\subsection{Complex thermal analysis}

Thermal analysis was performed on the STA 409-PC LUXX synchronous thermal analyzer, in platinum crucibles with pierced caps, in air environment. The possibility of getting the information from one sample by two independent methods of thermal analysis thermogravimetric (TG-DTG) and differential scanning calorimetry (DSC) was obtained in the synchronous thermal analyzer. The resulting graphic material was processed using the Proteus software. Thermal studies monitored thermal transformations in the samples at the temperature range $30-1000{ }^{\circ} \mathrm{C}$, and the intervals of transformations, maximum temperatures, and mass loss values corresponding to the conversion intervals were identified.

\subsection{X-ray powder diffraction (XRD)}

The X-ray powder diffraction study of raw materials and new growths in the hardened cement structure was conducted on the general-purpose diffractometer Bruker D8 ADVANCE. The powder method, and the method using the X-ray diffraction were used. For automated processing of diffraction spectra, the signal was recorded in digital form. Shooting mode: $\mathrm{Cu}$ K-radiation, $40 \mathrm{kV}$, $30 \mathrm{~mA}$, scan step $0.02^{\circ}$, speed $1^{\circ} / \mathrm{min}$.

In the phases identification during the qualitative $\mathrm{X}$ ray powder diffraction, the following features were taken into account:

1) the values of interplanar distances on the reference and decrypted x-ray diffraction patterns can differ from each other by up to $1 \%$, since this is due to the experimental error, the heterogeneity of the phase composition and, as a consequence, the possible overlap of reflections, the variability of the chemical composition and structural state of the components in the test substance;

2) phase identification was carried out throughout the X-ray pattern;

\subsection{Electron microscopy}

Electron microscopic studies the obtained soil cement samples were carried out using the scanning electron microscope REM-100U. The studies were carried out with the aim of determining the mineral composition of materials and studying the morphology of hydrated newgrowths, the surface of studied soil cement compositions.

\section{Results and discussion}

The mineralogical composition of the studied soil (light sandy loam) is represented by the following minerals: quartz $-70.3 \%$, feldspars - $26.9 \%$, clay minerals (mineral from the group of smectites, mica, chlorite) $-2.8 \%$.

Studies have shown that the complex additive based on organosilicon compound of OTES and SH electrolyte has a multifunctional effect. Thus, the introduction in the soil cement composition of the optimal amount of a complex additive led to increase the compressive strength up to $31.6 \%$, the bending tensile strength up to $35.2 \%$, and the frost resistance up to $62.3 \%$.

The phase composition of hydrated newgrowths and soil minerals in soil cement with the complex additives optimal content after 28 days of normal hardening was studied by DTA, XRD and electron microscopy.

Figure 1 shows that the control sample contains diffraction reflections of soil minerals, namely quartz (4.25; 3.34; 2.45; $2.28 \AA$ ), calcite (3.03 $\AA$ ), feldspar (3, 24; $3.19 ; 3.18 \AA)$, clay mineral $(4.47 \AA)$, as well as unhydrated Portland cement clinker minerals (2.8; 2.77; 2.69; $2.65 \AA$ ) and hydrated newgrowths - calcium hydroxide $(4.9 ; 2.63 \AA$ ). Interplanar distances are given in parentheses.

$\mathrm{X}$-ray pattern of the sample with complex additive notes the same peaks of soil minerals, unhydrated cement clinker minerals and hydrated newgrowths.

Clay minerals (layered aluminosilicates) are represented by minerals from the group of smectites $\left((\mathrm{Na}, \mathrm{Ca})_{0.33}(\mathrm{Al}, \mathrm{Mg})_{2}\left(\mathrm{Si}_{4} \mathrm{O}_{10}\right)(\mathrm{OH})_{2} * \mathrm{nH}_{2} \mathrm{O}\right), \quad$ mica ((K0.75(H3O)0.25)Al2(Si3Al)O10((H2O)0.75(OH)0.25) 2) and chlorite $\left((\mathrm{Mg}, \mathrm{Fe})_{3}(\mathrm{Si}, \mathrm{Al})_{4} \mathrm{O}_{10}(\mathrm{OH})_{2} *(\mathrm{Mg}, \mathrm{Fe})_{3}(\mathrm{OH})_{6}\right)$. The feldspars (skeleton aluminosilicates) are represented by minerals from the group of potassium feldspars $\left(\mathrm{K}\left[\mathrm{AlSi}_{3} \mathrm{O}_{8}\right]\right.$ ) and plagioclases $\left(\mathrm{Na}\left[\mathrm{AlSi}_{3} \mathrm{O}_{8}\right]\right.$, $\left.\mathrm{Ca}\left[\mathrm{Al}_{2} \mathrm{Si}_{2} \mathrm{O}_{8}\right]\right)$. The soil also contains a mineral from the group of amphibole actinolite - tremolite series $\left(\mathrm{R}_{7}\left[\mathrm{Si}_{4} \mathrm{O}_{11}\right]_{2}(\mathrm{OH})_{2}\right.$, where $\mathrm{R}=\mathrm{Ca}, \mathrm{Mg}, \mathrm{Fe}$.

Portland cement clinker minerals are composed of tricalcium silicate $\left(\mathrm{Ca}_{3} \mathrm{SiO}_{5}\right)$, dicalcium silicate $\left(\mathrm{Ca}_{2} \mathrm{SiO}_{4}\right)$, calcium aluminoferrite $\left(\mathrm{Ca}_{2} \mathrm{AlFeO}_{5}\right)$, and 


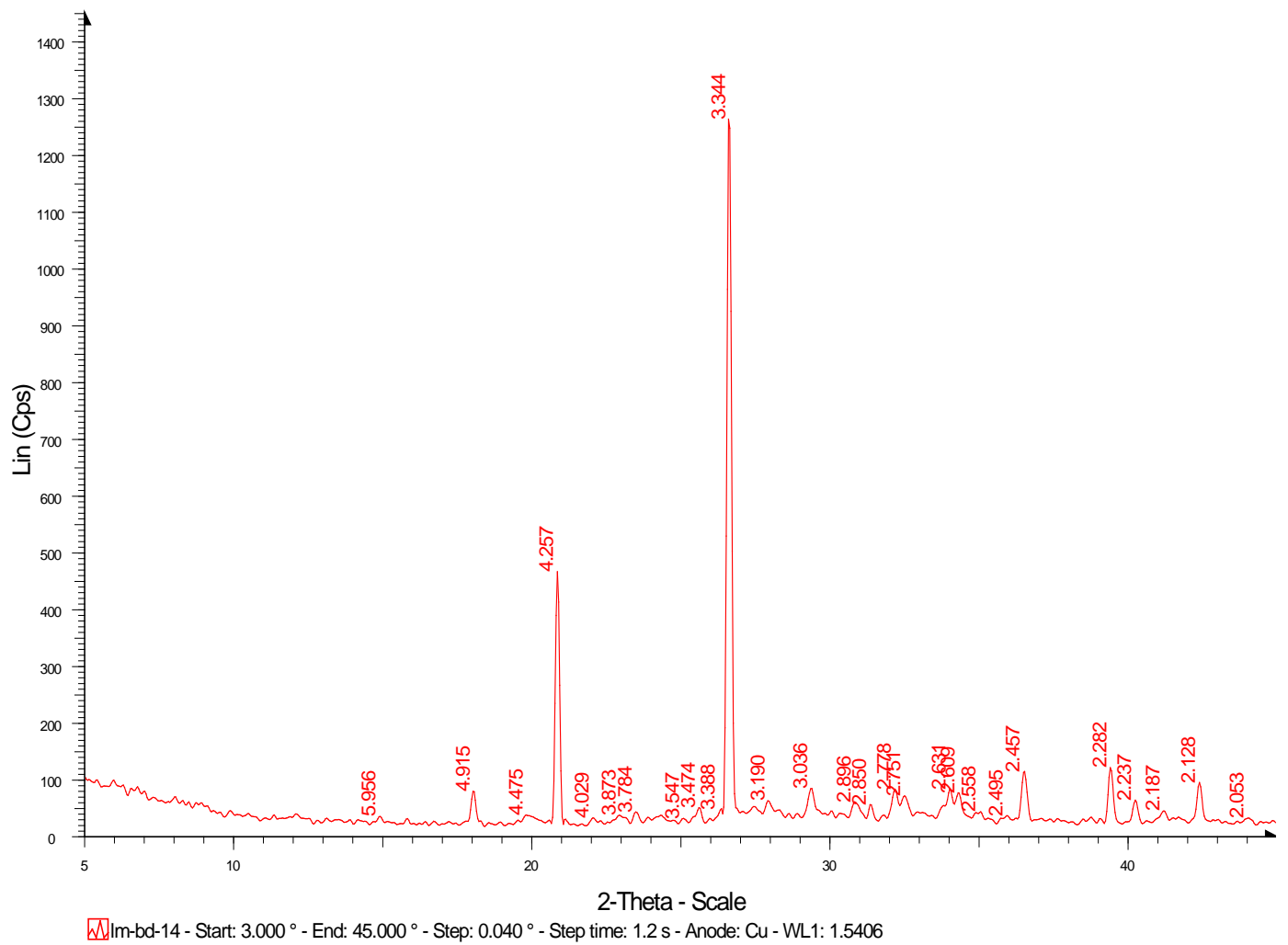

Fig. 1. X-ray pattern of cement samples.

tricalcium aluminate $\left(\mathrm{Ca}_{3} \mathrm{Al}_{2} \mathrm{O}_{6}\right)$. Due to their low total content in mixture with loam, the diagnosis of individual minerals is difficult.

Soil cement samples were also studied using differential thermal analysis. Endo and exothermic effects on the derivatograms of thermogravimetric TG, differential thermogravimetric DTG and differential calorimetric DSC curves of soil cement samples are shown in Figure 2.

The first endoeffect at temperature at $80-100^{\circ} \mathrm{C}$ of samples with complex additive and without it, corresponds to the free water evaporation temperature. The second endoeffect with a maximum at $164{ }^{\circ} \mathrm{C}$ was

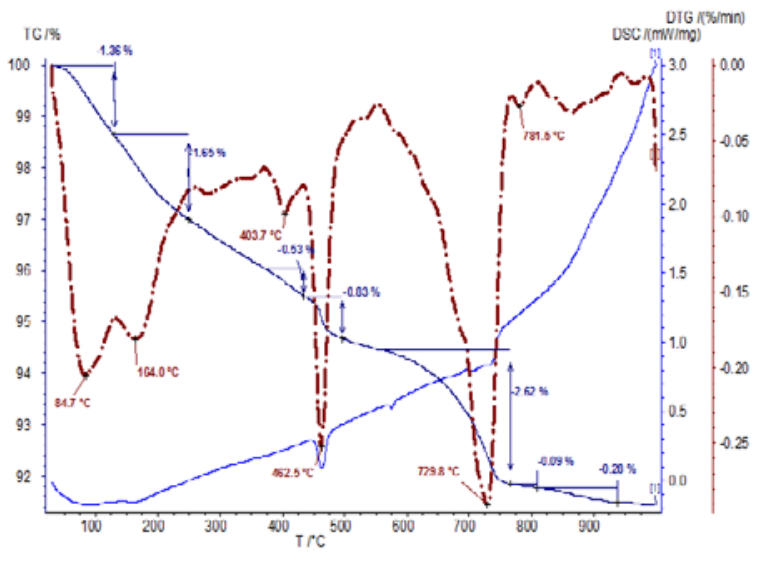

a) noted on the DTA curves of samples of the control composition and with the complex additive caused by the removal of loosely bound water from the gel-like mass of cement stone and adsorption water from minerals of the smectite group (montmorillonite, nontronite, beidellite). Obviously, the smaller mass loss of the modified composition is explained by the fact that with the introduction of a complex additive, the optimum soil moisture, and, consequently, the amount of water bound, decreased. The third endoeffect at temperature of $325-425{ }^{\circ} \mathrm{C}$ is associated with the dehydration of smectite group minerals. The difference in mass loss is explained by the saturation of the absorbing soil complex

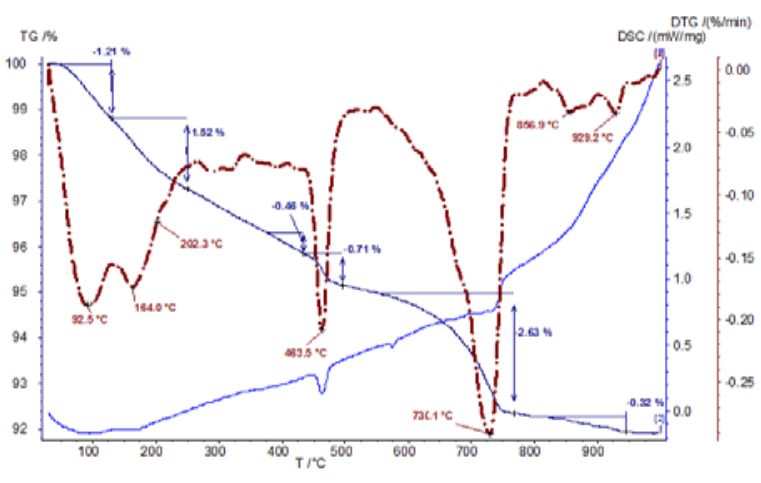

b)

Fig. 2. DTA curves of cement soil samples: a) control composition; b) composition with the complex additive. 


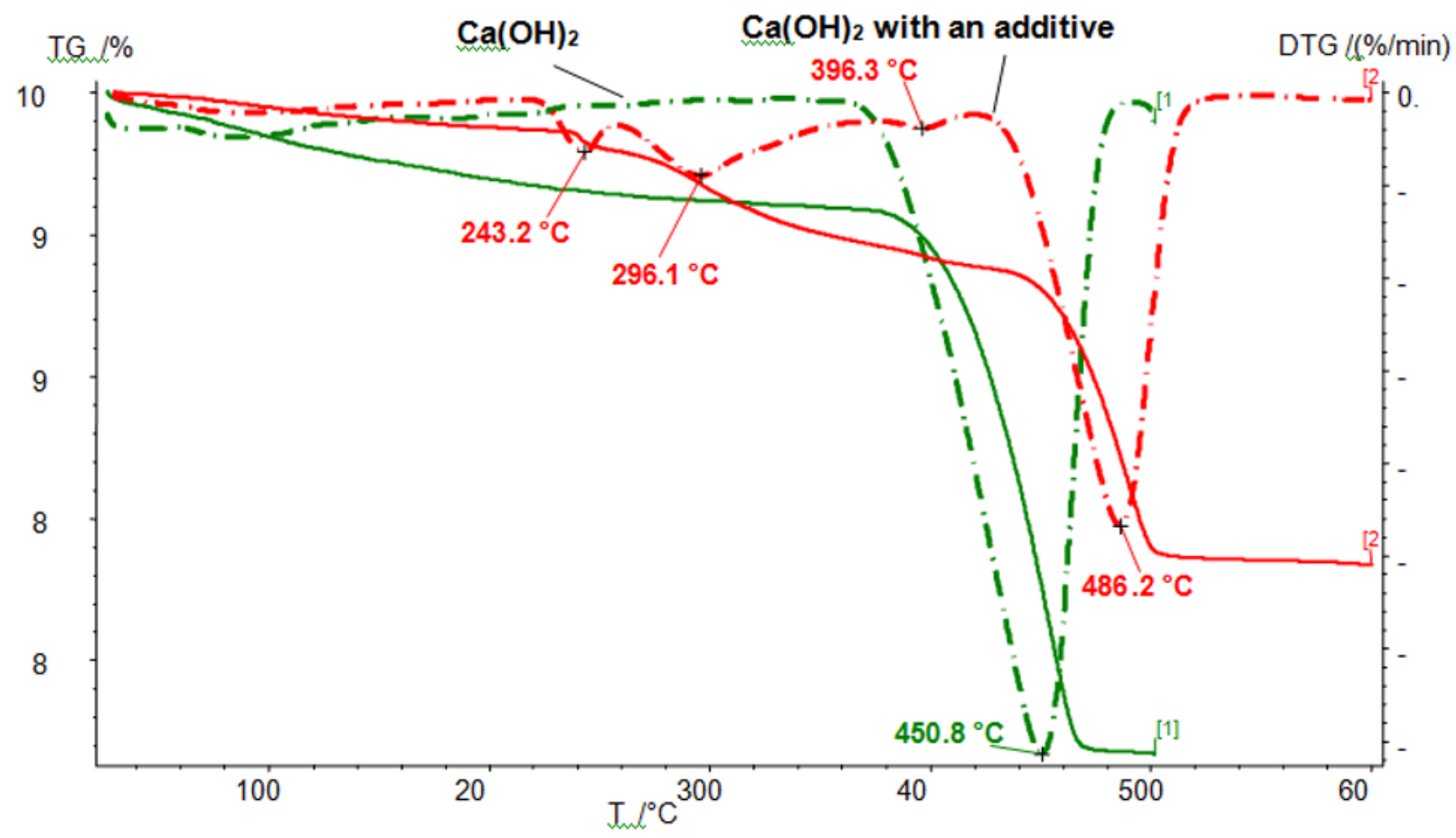

Fig. 3. DTA curves of calcium hydroxide samples of control composition and with the complex additive.

\section{by $\mathrm{Na}^{+}$ions}

The endo effect with maximum at $460-470{ }^{\circ} \mathrm{C}$ is caused by the calcium hydroxide dehydration. In this case, modified composition samples exhibit less weight loss, therefore, less formation of calcium hydroxide, which is confirmed by the differential thermal analysis of calcium hydroxide samples of the control composition and with the complex additive (Fig. 3) and by the studies of V.G. Batrakov. The $\mathrm{Ca}(\mathrm{OH})_{2}$ interaction with an organosilicon additive may explain the increase of physicomechanical properties the resulting material. A slight thermal effect at $550-560^{\circ} \mathrm{C}$ is associated with chlorite dehydration. At a temperature of $730{ }^{\circ} \mathrm{C}$, calcium hydrosilicate and calcium carbonate decompose. Endoeffects at a temperature of 830-930 ${ }^{\circ} \mathrm{C}$ are associated with the destruction of the lattice and amorphization of smectite group minerals. The difference in mass loss is also explained by the saturation of the absorbing soil complex by $\mathrm{Na}+$ ions

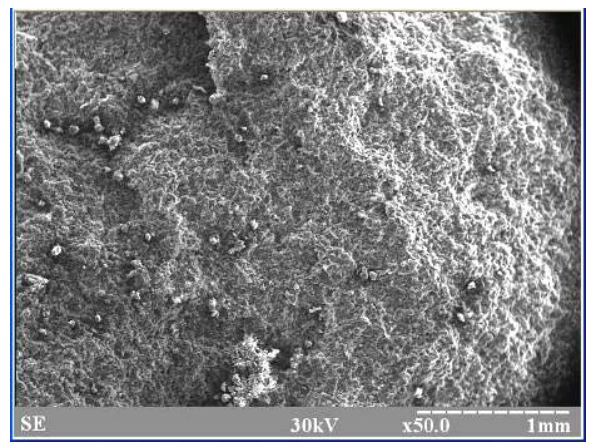

a) when the complex additive was introduced.

As a result of differential thermal analysis, we determined that the soil cement with complex additive was characterized by a smaller amount of free calcium hydroxide formed, as well as soil complex saturation by sodium ions, which, possibly, explains the increase of physical and mechanical characteristics.

As a result of differential thermal analysis, we determined that the soil cement with complex additive was characterized by a smaller amount of free calcium hydroxide formed, as well as soil complex saturation by sodium ions, which, possibly, explains the increase of physical and mechanical characteristics.

The surfaces of internal cleaved samples and their morphological features were studied by electron microscopy. Figure 4 shows the complex soil cement structure of control composition and with the complex additive.

The analysis of research results showed that the soil

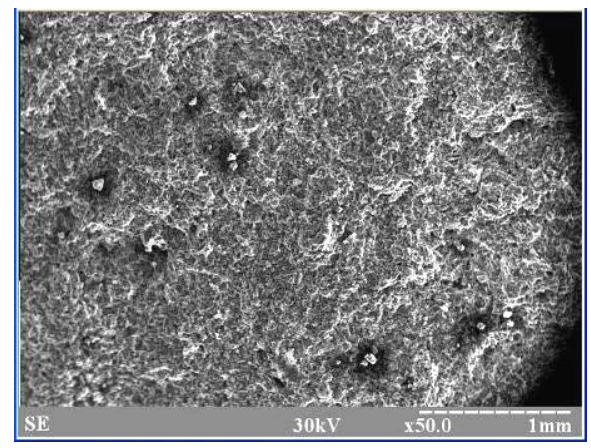

b)

Fig. 4. Electron microscopic images the soil cement samples: a) control composition; b) composition with the complex additive. 


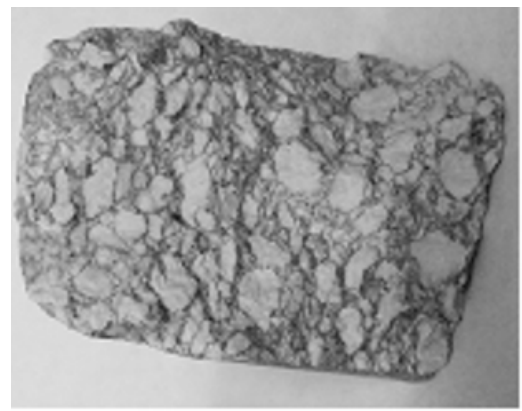

a)

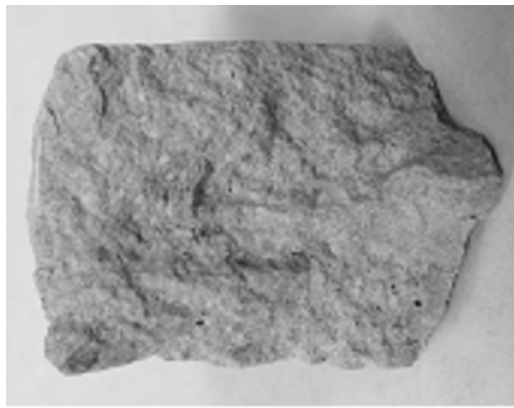

b)

Fig. 5. Photos of chips the kaolinite strengthened samples with $10 \%$ of cement: a) control composition; b) composition with the complex additive.

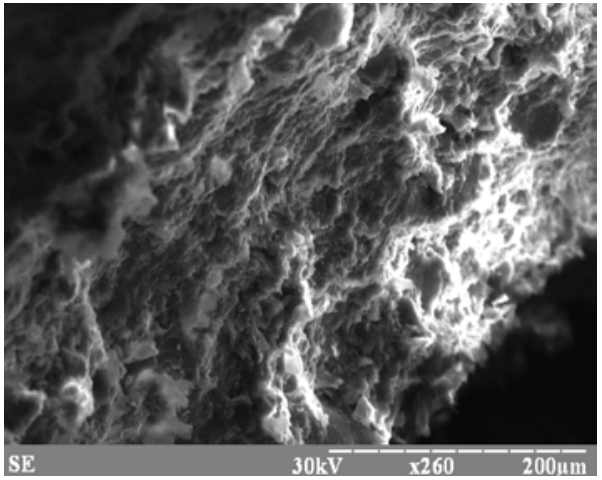

a)

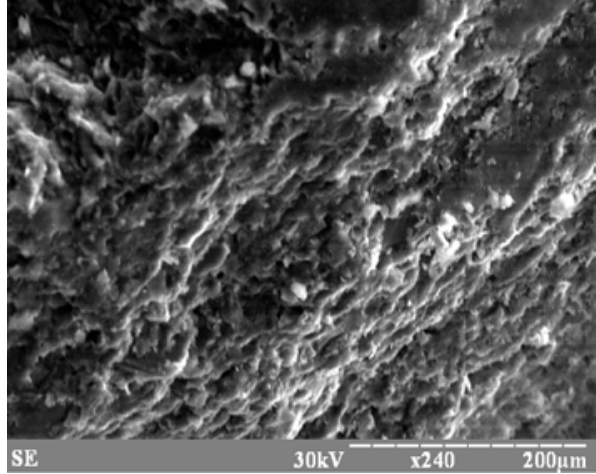

b)

Fig. 6. Electron microscopic images the kaolinite strengthened samples with $10 \%$ of cement: a) control composition; b) composition with a complex additive.

cement surface is dense packing of randomly arranged elongated particles of micron sizes, individual shells, pores and isometric grains. The surface texture is cryptocrystalline, pelitomorphic, with no tendency to peeling. The granular composition is homogeneous, the particle size does not exceed 100 microns. In the soil cement sample with complex additive (Fig. 4 (b)), the smaller amount of coagulated soil aggregates is observed in comparison with the sample without additive (Fig. 4. (a)), which makes the structure more dense and uniform. This is a consequence of the $\mathrm{NaOH}$ dispersing effect on the soil, thereby increasing the accessibility of the soil surface to introduced cement and their interaction completeness.

The electron microscopy study of kaolinite samples strengthened by cement confirms the dispersing complex additive effect. Figures 5 and 6 show photographs of chips and electron microscopic images of kaolinite strengthened samples with $10 \%$ of cement. In samples with the complex additive, the more homogeneous structure is observed in comparison with control samples.

\section{Conclusions}

1. The complex additive helps to increase the soil surface accessibility to the introduced cement due to the dispersing effect of sodium hydroxide, which leads to the formation of more dense and uniform soil cement structure.

2. It was found that the adsorption water amount associated with clay minerals is less when the complex additive is introduced into the soil cement due to saturation the soil complex by sodium ions.

3. It was determined that the soil cement with complex additive has a smaller amount of formed calcium hydroxide due to its interaction with organosilicon compound.

4. The structure of kaolinite strengthened by cement without complex additive is composed of large aggregated particles. Most of its surface is not bound by Portland cement, which, in turn, may become the material destruction center. In the structure of kaolinite strengthened by cement with complex additive, such aggregates are absent.

\section{References}

1. R. D. Starcher, C. E. Pierce, S. L. Gassman, and M. Faris, Adv. Civ. Eng. Mater. 7, 20170062 (2018)

2. S. Caro, J. P. Agudelo, B. Caicedo, L. F. Orozco, F. Patiño, and N. Rodado, Int. J. Pavement Eng. 20, 1425 (2019)

3. A. Thomas, R. K. Tripathi, L. K. Yadu, and S. Roy, Int. J. Earth Sci. Eng. 9, 1049 (2016)

4. P. Tharuna, P. T. Ravichandran, and K. Divya Krishnan, J. Mines, Met. Fuels 2018, 86 (2018) 
5. A. M. S. Haquie and M. L. Hart, in Environ. Sci. Eng. (2019), pp. 481-488

6. S. Burchill, P. L. Hall, R. Harrison, M. H. B. Hayes, J. I. Langford, W. R. Livingston, R. J. Smedley, D. K. Ross, and J. J. Tuck, Clay Miner. 18, 373 (1983)

7. S. Ng and J. Plank, Cem. Concr. Res. 42, 847 (2012)

8. T. Underwood, V. Erastova, and H. Chris Greenwell, Clays Clay Miner. 64, 472 (2016)

9. W. Hao, S. L. Flynn, T. Kashiwabara, M. S. Alam, S. Bandara, L. Swaren, L. J. Robbins, D. S. Alessi, and K. O. Konhauser, Chem. Geol. 529, (2019)

10. M. Wojciechowski, P. Baryła, and M. Lefik, Main Properties of Sands Hydrophobized by Alkoxysilane Emulsions (2014), pp. 1192-1201

11. J. L. Daniels, M. S. Hourani, and L. S. Harper, in 3rd World Coal Ash, WOCA Conf. - Proc. (2009)

12. J. L. Daniels, P. Mehta, M. Vaden, D. Sweem, M. D. Mason, M. Zavareh, and V. Ogunro, Int. J. Terrasp. Sci. Eng. 1, 19 (2009)

13. J. G. Dai, Y. Akira, F. H. Wittmann, H. Yokota, and P. Zhang, Cem. Concr. Compos. 32, 101 (2010)

14. E. A. Tokar, S. V. Vavrenyk, and S. G. Krasitskaya, in IOP Conf. Ser. Mater. Sci. Eng. (2017)

15. S. Li, W. Zhang, J. Liu, D. Hou, Y. Geng, X. Chen, Y. Gao, Z. Jin, and B. Yin, Coatings 9, (2019)

16. H. Czachor, S. H. Doerr, and L. Lichner, J. Hydrol. 380, 104 (2010)

17. X. Zhang, S. Li, T. Zhao, and Z. Jin, in Key Eng. Mater. (2015), pp. 504-509

18. V. M. Knatko, E. V. Shcherbakova, and M. V. Knatko, Vestn. Sankt-Peterburgskogo Univ. Seriya Geol. i Geogr. 2008, 82 (2008)

19. A. Marsh, A. Heath, P. Patureau, P. Evernden, and P. Walker, Constr. Build. Mater. 229, (2019)

20. T. Miranda, D. Leitão, J. Oliveira, M. CorrêaSilva, N. Araújo, J. Coelho, A. Fernández-Jiménez, and N. Cristelo, J. Clean. Prod. 242, (2020)

21. S. Contessi, L. Calgaro, M. C. Dalconi, A. Bonetto, M. Pietro Bellotto, G. Ferrari, A. Marcomini, and G. Artioli, J. Hazard. Mater. 382, (2020)

22. L. Mavliev, P. Bulanov, E. Vdovin, V. Zaharov, and A. Gimazov, ZKG Int. 69, 49 (2016) 